64 Erma Safitri : The Role of adaptive MSCs as an Attempt Regeneration of Spermatogenesis Process using

\title{
The Role of adaptive MSCs as an Attempt Regeneration of Spermatogenesis Process Using by Hypoxia Precondition In Vitro
}

\author{
Safitri E. ${ }^{1,2 *}$, Utama S. ${ }^{1}$, Bumi C. 2,3, Mulyani S. ${ }^{2,4}$, Susilowati H. ${ }^{2}$, Retnowati E. ${ }^{5}$, Purwati ${ }^{2,6}$, \\ Prasetyo R.H. ${ }^{7}$, Hariadi M. ${ }^{1}$, Rantam F. ${ }^{2,8}$ \\ ${ }^{1}$ Department of Veterinary Reproduction, Faculty of Veterinary Med, Universitas Airlangga. \\ ${ }^{2}$ Stem Cell Research and Development Center, Universitas Airlangga. \\ ${ }^{3}$ Department of Epidemiology and Biostatistics Public Health, Jember University. \\ ${ }^{4}$ Department of Dento maxilla Facial Radiology, Faculty of Dentistry, Universitas Airlangga. \\ ${ }^{5}$ Department of Clinical Pathology, Faculty of Medicine, Universitas Airlangga. \\ ${ }^{6}$ Internal Medicine Department of RSUD Dr. Soetomo Surabaya. \\ ${ }^{7}$ Department of Parasitology, Faculty of Medicine, Universitas Airlangga. \\ ${ }^{8}$ Department of Microbiology and Virology, Faculty of Veterinary Med, Universitas Airlangga. \\ *Corresponding author: rma_fispro@yahoo.com
}

\begin{abstract}
The aim of this research was to obtain to get adaptive MSCs by an treatment in hypoxia precondition in viro culture. Ini this research, hypoxia precondition was to be given $3 \% \mathrm{O} 2$ concentration and compared to those of normoxia culture in $\mathrm{O} 2>20 \%$. Results showed that under 3\% O2 concentration, CD105+ and CD45- by flowcytometri, immunocytokimia and immunofluorescence didn't experience of change (undifferentiated). Meanwhile under $>20 \%$ O2 concentration, cells have experienced of change (not undifferentiated again), that was indicated with CD105+ become decrease and CD45- increase by flowcytometri, immunocytokimia and immunofluorescence. Conclusion, in this research showed that hypoxia precondition with $3 \% \mathrm{O} 2$ concentration very support MSCs to constantly adaptive before transplantated for disturbance of spermatogenesis process, because did'nt experience become progenitor cells was not expectation (still undifferentiated).
\end{abstract}

\section{Key words: MSCs, hypoxia precondition $3 \% \mathrm{O}_{2}$ concentration, adaptive.}

\section{INTRODUCTION}

Cell therapy using mesenchymal stem cells (MSCs) provides a very promising solution for degeneration case where recovering through medical or surgical intervention is impossible like as in the case of restoring and regenerating germ cells and testis tissues (Blanchard et al., 2008). However, the low viability specially low adaptive of the transplanted stem cell in degenerative testis to differentiate into spermatogonia cells causes the limitation of the efficacy of this therapy (Kenichiro et al., 2005 and Tang et al., 2005). A study on stem cell by Suzuki et al., (2004) revealed that $93 \%$ of the stem cells injected died three days after injection. This indicates that microenviroment in the degenerative testis tissue or body organs are not conducive for survival of the stem cells. The estimated mechanism accounted for the decreasing function of stem cells are the high amount of the stem cells experience differentiated 
before transplantation to patient with spermatogenesis precess decreassed (Calvallini, 2006).

Therefore the undifferentiated of MSCs before implantation very important for stem cells' adaptive and increase the efficacy of stem cell

\section{MATERIALS AND METHODS}

Rabbit was anesthetized at the coxygea area (anasthetized local). MSCs was harvested by an aspiration of bone marrow at the middle of femur bone below the condylus. Aspirate from bone marrow was placed in hepaninized tubes. Sample in tube was placed in thermos maintained at $4{ }^{\circ} \mathrm{C}$ during transportation to be processed in laboratory.

Aspirate from bone marrow was transferred into $15 \mathrm{ml}$ sterile blue capped tubes then tube was rinsed twice with $5 \mathrm{ml}$ sterile Phosphate Buffered Saline (PBS). PBS was topped up to a total volume of $8 \mathrm{ml}$. Diluted sample was loaded over a same volume of Ficoll in a separate $15 \mathrm{ml}$ tube. Centrifugation was performed at $1600 \mathrm{rpm}$ for 15 minutes at room temperature. After centrifugation cells were collected from Ficoll-PBS interface using sterile pasteur pipette and transferred into $15 \mathrm{ml}$ tube. Cells were then resuspended in PBS up to a total volume of $15 \mathrm{ml}$. Tube was inverted gently 5 times to homogenize the suspension. Tube was then centrifuged again at $1600 \mathrm{rpm}$ for 10 minutes. Supernatant and floating cells were discarded and cell pellet was resuspended in $6 \mathrm{ml}$ of a MEM prior to incubation. Cells were plated in $10 \mathrm{~cm}^{2}$ plates and incubated at $37^{\circ} \mathrm{C}$ in a therapy. Therefore adaptation of the stem cells with hypoxiaprecondition during in vitro culture adjusted to the in vivo niche of the stem cell need to be conducted in an attempt to increase viability at the time of transplantation to patient with spermatogenesis precess decreassed.

humidified atmosphere containing 5\% $\mathrm{C}^{2}$ for 24 hours to let the cells adhere. After 24 hours, media and non-adherent cells were discarded. Adherent cells were rinsed twice using $5 \mathrm{ml}$ of PBS. Ten ml of fresh a MEM was then added into dish and the dish was returned into the incubator. Culture was observed daily under an inverted microscope. Every 4 days medium was changed, preceeded by a rinse using $10 \mathrm{ml}$ PBS then $10 \mathrm{ml}$ of fresh a MEM were replaced. Culture was continued until approximately 75$80 \%$ confluence was attained. After confluence, cells were passaged into several dishes for subculture (Rantam et al., 2009). Passage was conducted 3 times, then cells were divided into two hypoxia precondition treatments of 3\% in hypoxia chamber inside $5 \% \mathrm{C}^{2}$ incubator while another treatment was the use of $>20 \%$ oxygen (normoxya).

\section{RESULT}

Results of this research showed that under $\begin{array}{llll}\text { hypoxia precondition under } & 3 \% & \mathrm{O}_{2}\end{array}$ concentration, CD105+ and CD45- in MSCs culture didn't experience of change (still undifferentiated) by flowcytometri, immunocytokimia and immunofluorescence. Meanwhile under $>20 \% 02$ concentration, cells 
have experienced of change (not undifferentiated again), that was indicated with CD 105+ become decrease and CD45- increase by flowcytometri, immunocytokimia and immunofluorescence

(Figure 1-5).

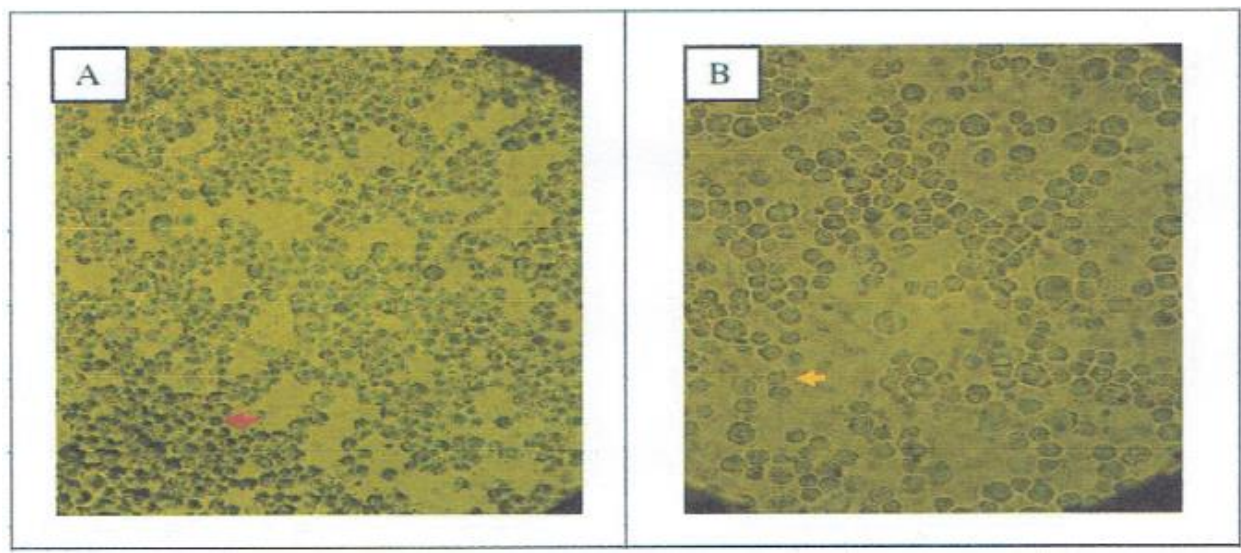

Figure 1. Identificated by immunocytokimia after hypoxia precondition ( $3 \% \mathrm{O}_{2}$ concentration) in culture MSCs A. Positive expresion of CD105 (CD105+) (red arrow head)

B. Negative expression of CD45 (CD45-) (yelow arrow head)

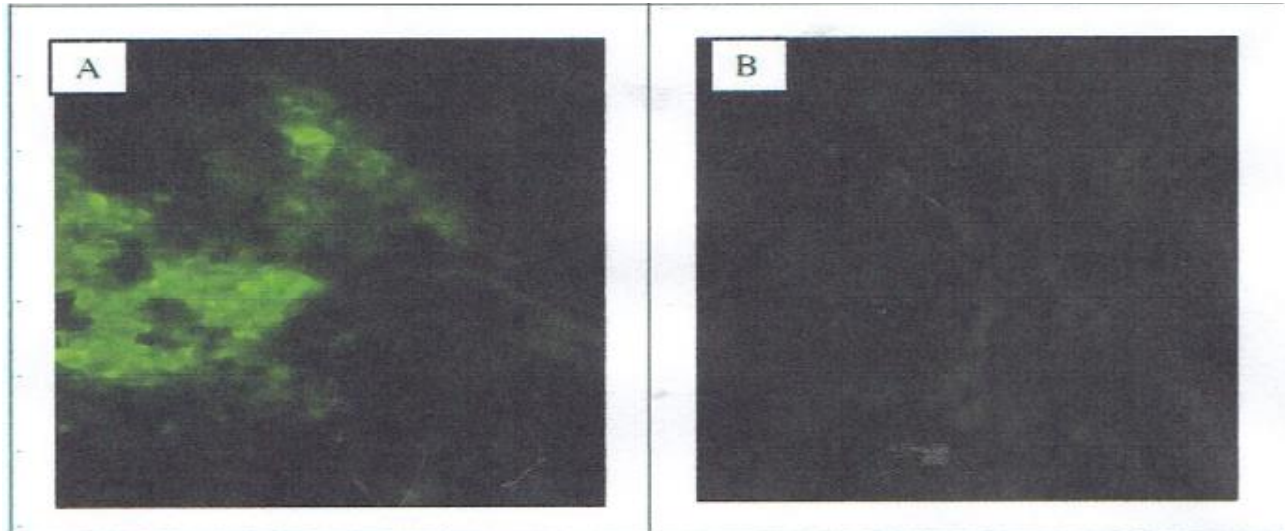

Figure 2. Identificated by immunofluorescence after hypoxia precondition ( $3 \% \mathrm{O}_{2}$ concentration) in culture MSCs. A. Positive expresion of CD105 (CD105+), green fluorescent B. Negative expresion of CD45 (CD45-).

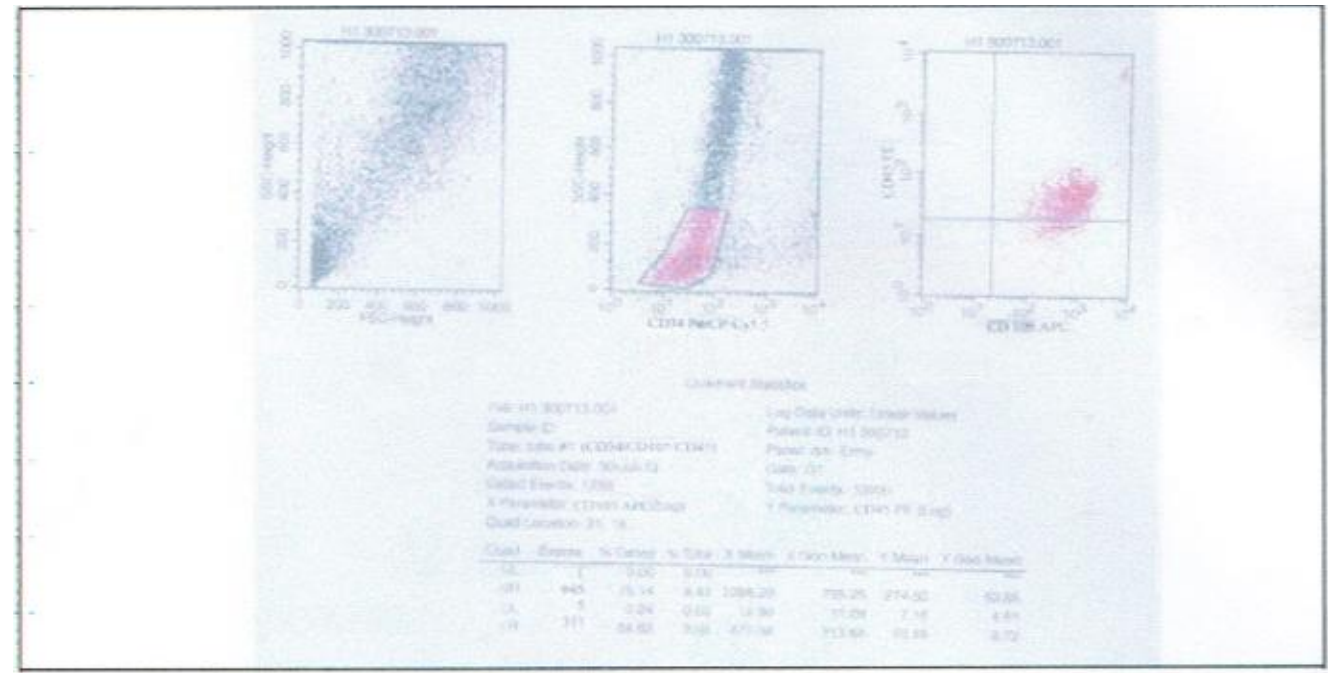

Figure 3. Identificated by fluocytometri after hypoxia precondition ( $3 \% \mathrm{O}_{2}$ concentration) in culture MSCs. Positive expresion of CD105 with amount 1256. Meanwhile CD34 and CD45 negative with amount 5 and 1. 


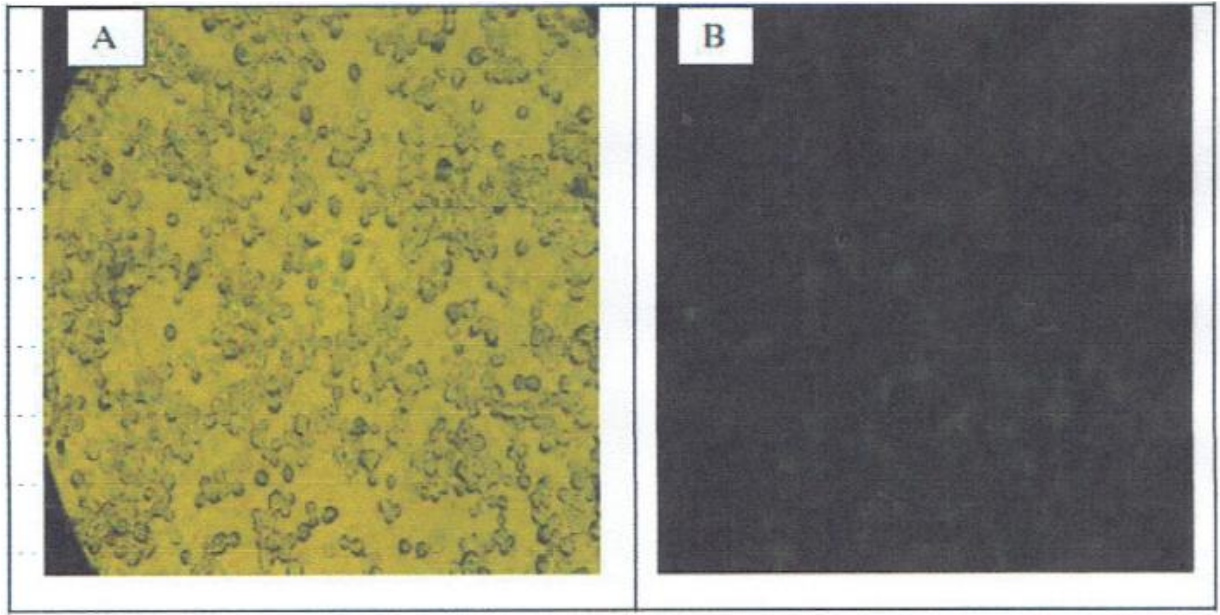

Figure 4. Normoxya group with $\mathrm{O}_{2}$ concentration $>20 \%$.

A. CD105+ was decreased, indicated by immunocytokimia.

B. CD105+ was decreased, indicated by immunofluorescence.

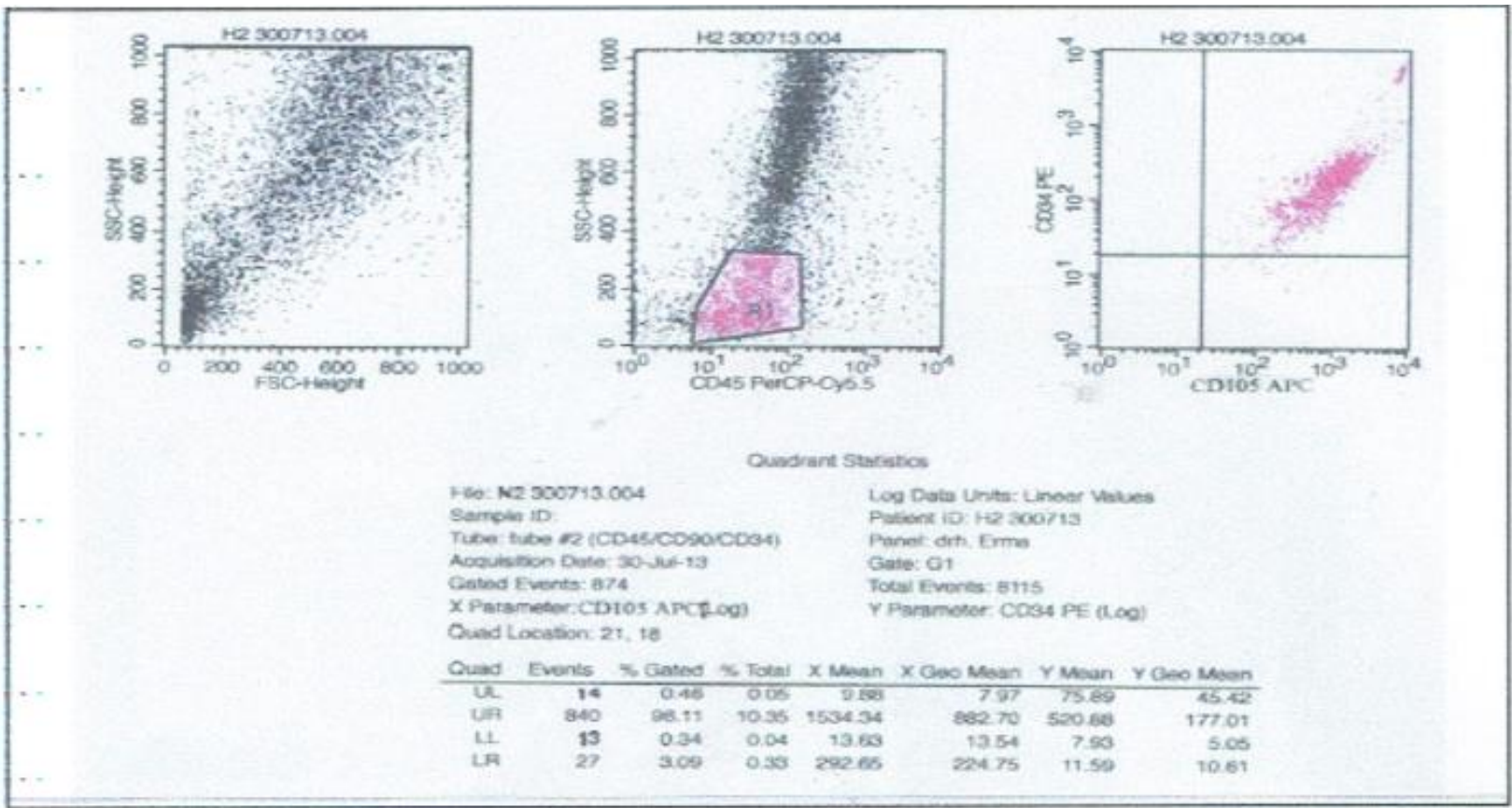

Figure 5. Identificated by fluocytometri at Normoxya group with $\mathrm{O}_{2}$ concentration $>20 \%$. Positive expresion of CD105 with amount 867. Meanwhile CD34 and CD45 negative with amount 14 and 13.

\section{DISCUSSION}

From the result of this research it could be explained as follows: that hypoxia precondition 3\% $\mathrm{O} 2$ concentration caused inhibiting Prolyl hidroxylases (PHDs) enzim expresion. It's cause complex Hypoxia Inducible Factor-I (HIF-1). This complex caused cell cycle arrest genes. Furthermore cell cycle arrest genes expresion, after 48 hours caused plurypoteney genes like
$\mathrm{OCT}_{4}, \quad \mathrm{SOX}_{2}, \quad$ NANOG and REX-I.

Plurypotency genes estimated activated by Hypoxia Inducible Factor $2 \alpha$. (HIF $2 \alpha$ ) after inisiation by Hypoxia Inducible Factor $2 \alpha$ (HIF $2 \alpha)$. The plurypotency genes to influence MSCs not experience of differentiation.

Therefore MSCs with hypoxia precondition 3\%

$\mathrm{O} 2$ concentration very support MSCs to 
constantly adaptive before transplantated for disturbance of spermatogenesis process, because did'nt experience become progenitor cells was not expectation (still undifferentiated).

Hypoxia precondition 3\% O2 concentration caused applied affected HIF-la release from van Houpel Lindau (vPL) and accumulated in nucleus. The high level of HIF-lo would inhibit Reactive Oxygen Species (ROS) that acted as free radical (Hamanaka and Chandel, 2010). The inhibition of ROS would inhibit the expression of protein genes P53 and P21. Therefore, cell cycle arrest genes were sensitized, which ended up with slow proliferation and maintenance of stem cells (Suda et al., 2011). This maintenance was also supported by the reduced ROS by the role of HIF-1 $\alpha$ therefore p53 gene expression was inhibited. The inhibition of p53 gene expression caused an inhibition of the opening of

\section{REFERENCES}

Blanchard K.T., J. Lee, and K. Boekelheide. 1998. Leuprolide, a GonadotropinReleasing Hormone Agonist, Reestablishes Spermatogenesis After 2,5- Hexanedione-Induced Irreversible Tsticular Injury in the Rat, Resuting in Normalized Stem cell Factor Expression. Endocriology.139(1):236-244.

Cavallini G. 2006. Male idiopathic oligoasthenoteratozoospermia.

Asian J. Androl., 8(2): 143-157.

Hamanaka RB and NS Chandel. 2010. Mitochondrial Reactive Oxygen Species Regulate Cellular Signaling and Dictate mitochondrial membrane pt pore. Therefore, cytochrome $\mathrm{C}$ that acted as apoptotic protease activing factor-I (APAF-I) caused inhibition of the release of various caspases (Caspase 9 and Caspase 3) as apoptotic cascade. The inhibition of P53, cytochrome $\mathrm{C}$ and caspases would cause the inhibition of cell death of the cultured stem cells. Meanwhile, the decreased P21 caused an inhibition of the active cycling cell which prevented cell senescence process from happening.

\section{CONCLUSION}

From the research results, it could be concluded that hypoxia precondition with $3 \% \quad \mathrm{O}_{2}$ concentration very support MSCs to constantly adaptive before transplantated for disturbance of spermatogenesis process, because did'nt experience become progenitor cells was not expectation (still undifferentiated).

Biological Outcomes Trends Biochem. Sci., 35: 505-513.

KenichiroH., N. Noritoshi, I. Takashi, T. Itoh., S. Murakami, Y. Shimizu,W. Taki, K. Miyatake,K. Kangawa. 2005. Adrenomedullin Enhances Therapeutic Potency of Mesenchymal Stem Cells after Experimental Stroke in Rats. Stroke36: 853-858.

Rantam FA, Ferdiansyah, Nasronudin and Purwati. 2009. Stem Cell ExplorationMethods of lsolation and Culture FirstEd. Airlangga University Press. Surabaya. 
Suda T, Takubo Kand Semenza GL. 2011. Cell

Stem Cell Review. Metabolic Regulation of ematopoietic Stem Cells in Hypoxic Niche. Cell StemCell., 9: 296-310.

Suzuki K, Murtuza B and Beauchamp JR. 2004. Dynamics and Mediators of Acute Graft Attrition After Myoblast Transplantation to the Heart.FASEB J., 18: 1153-1155.

Takubo K, Goda N, Yamada W, IriuchishimaH, Ikeda E, Kubota Y, Haruko S, Jhonson RS, Hirao A, SuematsuM and Suda T. 2010. Regulation of the HIF-1 Level is Essentialfor Hematopoietic Stem Cells. Cell Stem Cell., 7: 391-402.

Tang Y.L., Y.C. Zhang, L.P. Qian, Shen, and M. Phillips (2005). Improved Graft Mesenchymal Stem Cell Survival in Ischemic Heart with a Hypoxia regulated Heoxygenase 1 Vector. J. Am. Coll. Cardiol.46: 1339-1350. 